\title{
Some issues in modelling of ground support using the three-dimensional distinct element method
}

\author{
N Bahrani University of Toronto, Canada \\ J Hadjigeorgiou University of Toronto, Canada
}

\begin{abstract}
Numerical models are an integral part of the rock engineering arsenal that are applied to a wide range of practical problems. The choice for a particular numerical code is based on the capacity of a code to represent the boundary conditions, adequately capture the material behaviour and capture the pertinent failure mechanisms. It follows that there could be more than one code suitable for a particular problem. In this respect, the choice for a code will be dictated by a series of technical and practical trade-offs. This paper addresses issues associated with the explicit simulation of jointed rock mass and ground support in numerical models. Although various types of ground support elements have been implemented in most numerical analysis software packages, their practicality and applicability for realistic simulation of ground support have not received a high level of technical scrutiny. This paper focuses on explicit simulation of a jointed rock mass and ground support using the three-dimensional distinct element code (3DEC), which is based on the distinct element method (DEM). The calibration of the numerical model was conducted with reference to the results obtained from instrumented trials at the George Fisher mine, Queensland, reported by the Australian Centre for Geomechanics. In particular, the investigation considers the response of the ground support system, consisting of both reinforcement and surface support elements to the excavation of nearby stopes. It was demonstrated that the DEM model was capable of realistically simulating the ground deformation and the support behaviour monitored at different stages of mining cycles.
\end{abstract}

Keywords: ground support, SMART (stretch measurement to assess reinforcement tension) cable, drift convergence, 3DEC (three-dimensional distinct element code), model calibration, DEM (distinct element method)

\section{Introduction}

Numerical models are widely used in mining geomechanics to solve a range of user-defined problems. In theory, the choice for a particular numerical code is based on the capacity of a code to represent the boundary conditions, adequately capture the material behaviour and the pertinent failure mechanisms. In practice, the choice for a numerical code is more subjective, with other factors such as user's familiarity with a particular software, data availability and variability, perceived need for complexity and computational constraints come into play.

The use of simple models that capture the salient parts of a user-defined model are attractive and provide useful information (Starfield \& Cundall 1988). Irrespective of the model employed, it is imperative that the user gains confidence in the model. This is usually accomplished through a rigorous calibration process that often requires considerable effort. Quite often, the need for sophisticated numerical models may not be justified for a variety of reasons. In certain cases, however, the nature of the problem may require the use of a numerical method that can manage a high degree of complexity. An example of this problem is the explicit simulation of jointed rock mass and rock reinforcement and support.

This paper reports on the use of a three-dimensional (3D) code, 3DEC (Version 5), which is based on the distinct element method (DEM) for explicitly simulating jointed rock mass and ground support. It is an extension of the work by Sweby et al. (2016a), who used a 3D continuum model for an instrumented and supported section of a drift at the George Fisher mine, Queensland. 
The main focus of the present work is on the explicit representation of rock mass discontinuities, rock reinforcement and surface support in the 3D discontinuum model. The pursued modelling strategy in this investigation did not aim to fully reproduce the site conditions and the full behaviour of the reinforcement and support as mining advanced. It focused on the necessary trade-offs to construct a working model that provided adequate representation of the performance of ground support.

\section{Background}

The choice of a numerical method is influenced by a multitude of factors. Lorig and Varena (2013) suggest that 2D and 3D continuum methods are appropriate for weak rock masses, while discontinuum methods are used to model structurally controlled instability. Moreover, both continuum and discontinuum methods are used to capture brittle rock failure.

The use of 3D models introduce a significant degree of complexity and require further constraints regarding data availability and model calibration. Example applications of the use of both continuum and discontinuum models on ground support in mining have been presented, amongst others, by Lilley et al. (2013) using Abacus, Vakili et al. (2013) and Sweby et al. (2016a) using FLAC3D, and Karampinos et al. (2015) using 3DEC. The 3DEC model used to explicitly simulate jointed rock mass and ground support for this mining case study was constructed based on field and instrumentation data provided by Sweby et al. (2016b).

The Australian Centre for Geomechanics (ACG) has an ongoing research project on the use of ground support in mining. As part of this project, Sweby et al. (2016b) reported on a field trial at the George Fisher mine, where a comprehensive monitoring campaign was conducted in an effort to capture the behaviour of ground support as mining progressed. The George Fisher mine, located approximately $22 \mathrm{~km}$ north of Mount Isa, Queensland, extracts lead, zinc and silver from deformed and metamorphosed Proterozoic stratiform deposits hosted by dolomitic and carbonaceous sediments of the Urquhart Shale. The ore is mined by a combination of benching and transverse open stoping.

Detailed information on the instrumentation project has been provided by Sweby et al. (2016b). Different monitoring methods included closure measurements using tape extensometer and photogrammetry techniques, shotcrete liner strain measurement using vibrating wire strain gauges and cable bolt load measurement using the SMART (stretch measurement to assess reinforcement tension) cables (DeGraff et al. 1999), installed in a fan around the excavation perimeter.

The layout of the George Fisher mine, including the upper and lower stopes and the developments, is shown in Figure 1(a). Two sites (referred to as the North and South sites) were made available for instrumentations, both on the 17 Level, approximately 1,060 m below surface (Figure 1(b)). At the time of the installation, the North and South sites were both outside the stoping fronts, in the stress abutment zone. The mining schedule, at the time of installation, dictated that the mining front would progress beyond both sites during the project timeframe. Figure 1 (c) shows three nearby stopes (21, 23 and 29), which were excavated after the instrumentation installation at the North site. 

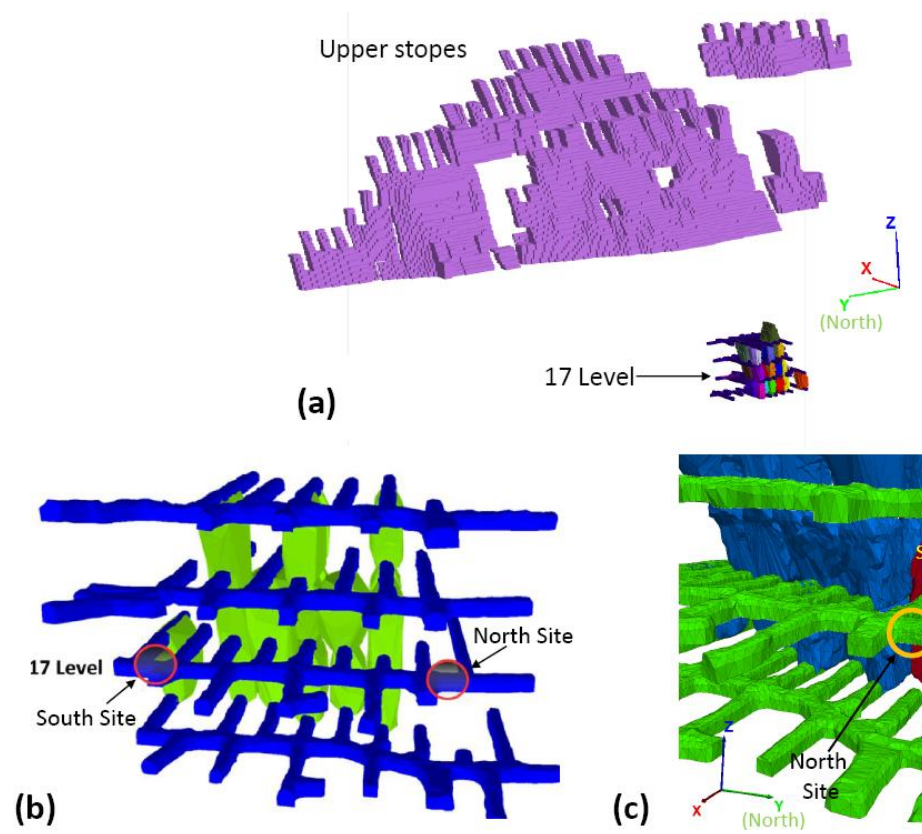

(c)

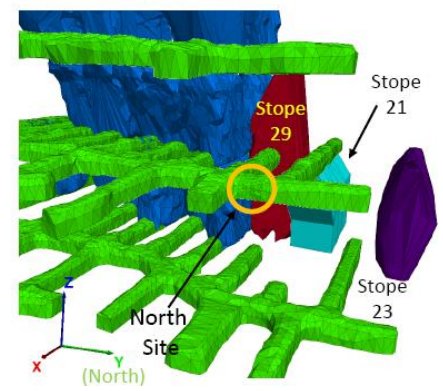

Figure 1 George Fisher mine showing: (a) mine layout including upper stopes, development and stopes adjacent to the monitoring sites; (b) location of instrumentation trial sites on the 17 Level and the excavated stopes at the commencement of the installations in late 2014 and early 2015 (modified from Sweby et al. 2016a); and, (c) stopes 21, 23 and 29 relative to location of the North site

\section{Three-dimensional distinct element method model}

\subsection{Modelling strategy}

A fundamental question in constructing a numerical model is whether a $2 \mathrm{D}$ approach would be adequate for a specific problem. As indicated earlier, the focus of this paper is the simulation of ground support at the North site and its response to the excavation of nearby stopes. It is seen from Figure 1 that the geometry at the North site is complex and cannot be approximated by a 2D plane strain approach.

A further question is whether a continuum model can capture the rock mass behaviour during the early and later stages of mining. In this case study, Sweby et al. (2016a) reported that they had some success with FLAC3D in this regard. The present investigation aimed to consider the use of a 3D discontinuum model capable of explicitly simulate rock mass discontinuities and ground support. The commercially available code, 3DEC, developed by Itasca Consulting Group, Inc. (2013), was used to simulate the discontinuous nature of the rock mass, the surface support, rock reinforcement, and the SMART cables used to monitor rock mass deformation at the North site. It was recognised that the use of 3DEC would require a series of assumptions and further trade-offs in order to run a time-efficient model.

A practical constraint is running a time-efficient numerical model that can capture the drift scale structural complexity, but also the impact of mine scale stopes near the drift. This required some simplifications. The first simplification was made possible by having access to the results of analyses on the same site, conducted using FLAC3D. It was found from the results of the FLAC3D analysis by Sweby et al. (2016a) that the presence of the upper stopes (shown in Figure 1(a)) and those in the lower level of the mine far from the North site (shown in Figure 1(b)) had minor impact on the induced stresses and displacements near the drift at the North site. Consequently, they were not considered in the present simulations. This significantly reduced the run time of the model.

Further simplifications in the 3DEC model included the geometry of the drift and the stopes. As an example, Figure 2 demonstrates the difference between the actual drift geometry at the North site obtained from photogrammetry techniques and the approximated drift geometry built in 3DEC. The two profiles in Figure 2(a) were obtained from scanning the drift before and after the application of shotcrete. 

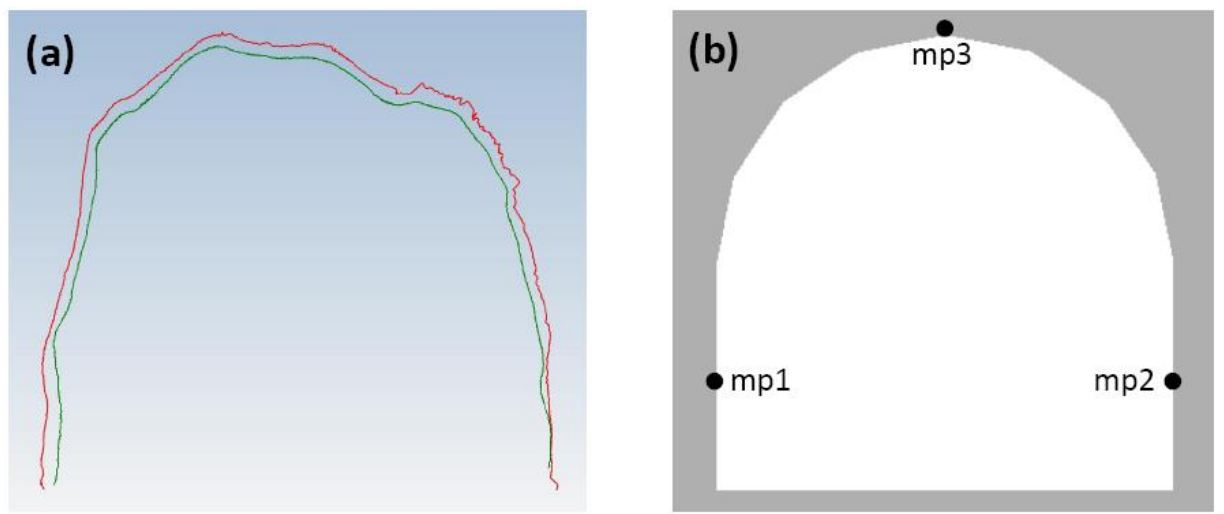

Figure 2 Comparison between: (a) drift geometry at the North site obtained from photogrammetry technique; and, (b) approximate drift geometry build in 3DEC ( $\mathrm{mp} 1$ to $\mathrm{mp} 3$ are the points used to monitor the deformation of the drift)

\subsection{Model construction and sequencing}

A $400 \times 400 \times 400 \mathrm{~m}$ 3DEC model (Figure 3(a)) was built to simulate a $90 \mathrm{~m}$ section of the main drift and the stopes near the North site (Figure 3(b)). The main motivation in the use of a discontinuum model was to capture the jointed nature of the rock mass. A practical approach adopted for this purpose was to divide the 3DEC model into continuum and discontinuum zones. The discontinuum zone is a $24 \times 24 \times 8 \mathrm{~m}$ block, in which the discontinuous nature of the rock mass at the North site was explicitly simulated. This discontinuum block was embedded in a $35 \times 35 \times 45 \mathrm{~m}$ continuum block with a ubiquitous joint material model. The rock mass outside this ubiquitous jointed block was simulated as an elastic material. Figures $4(a)$ and $4(b)$ show the continuum ubiquitous jointed block and the discontinuum block representing the rock mass at the North site, respectively. It can be seen from Figures 4(c) and 4(d) that the discontinuum block consists of three joint sets, with two persistent and one non-persistent joint set. Further information about these joint sets, in terms of geometry (orientation and spacing) and properties, are provided in Section 3.4. Figure 5 illustrates how closely the constructed 3DEC model resembles the discontinuous nature of the rock mass surrounding the drift.

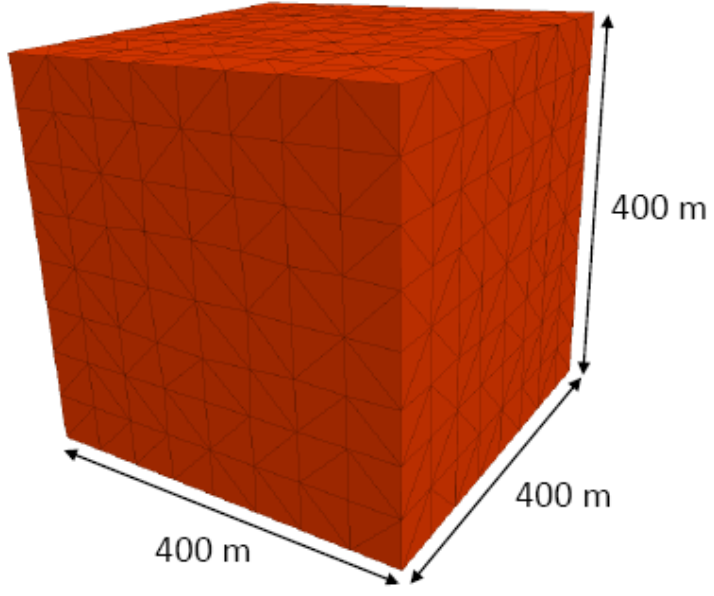

(a)

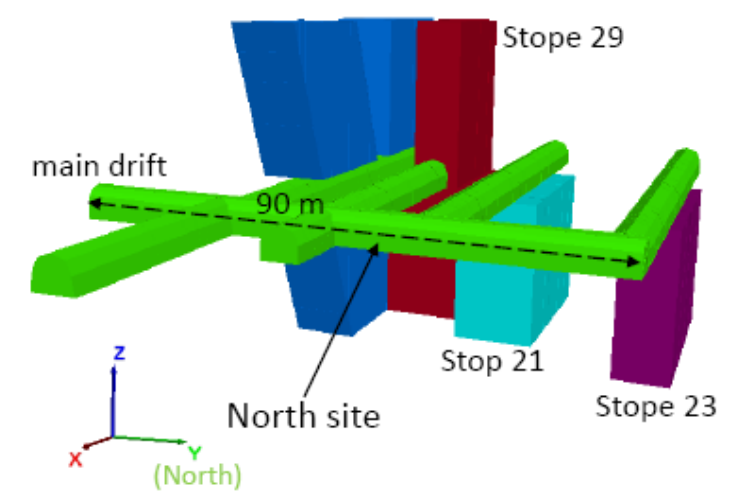

(b)

Figure 3 (a) 3DEC model outer boundaries; and (b) developments and mining stopes near the North site 

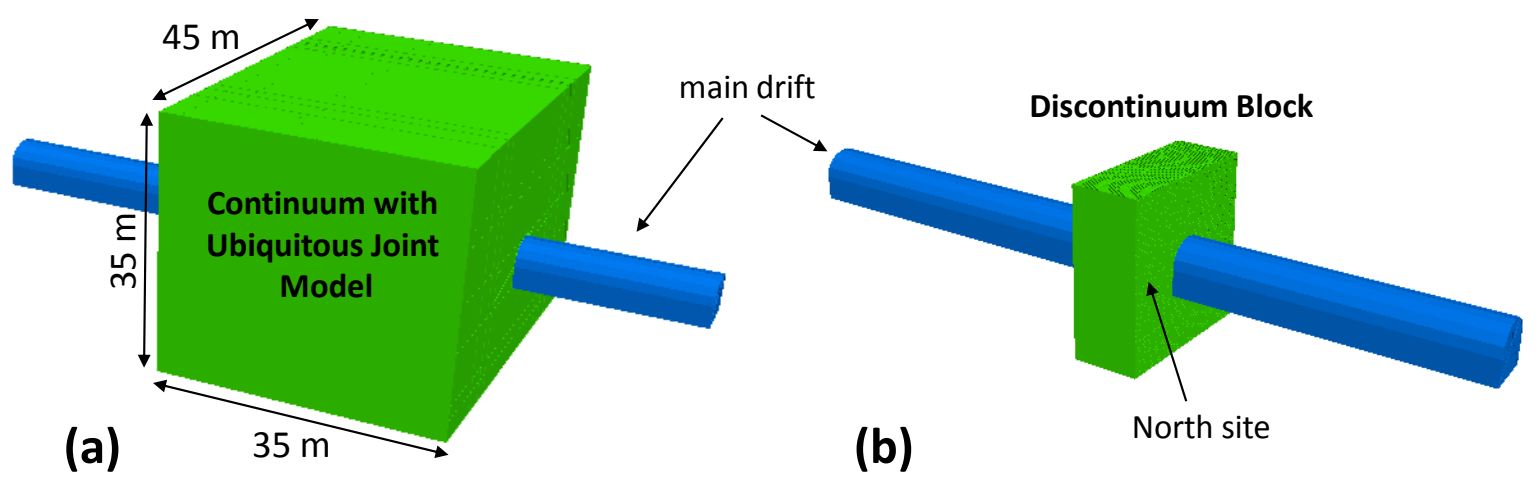

(b)
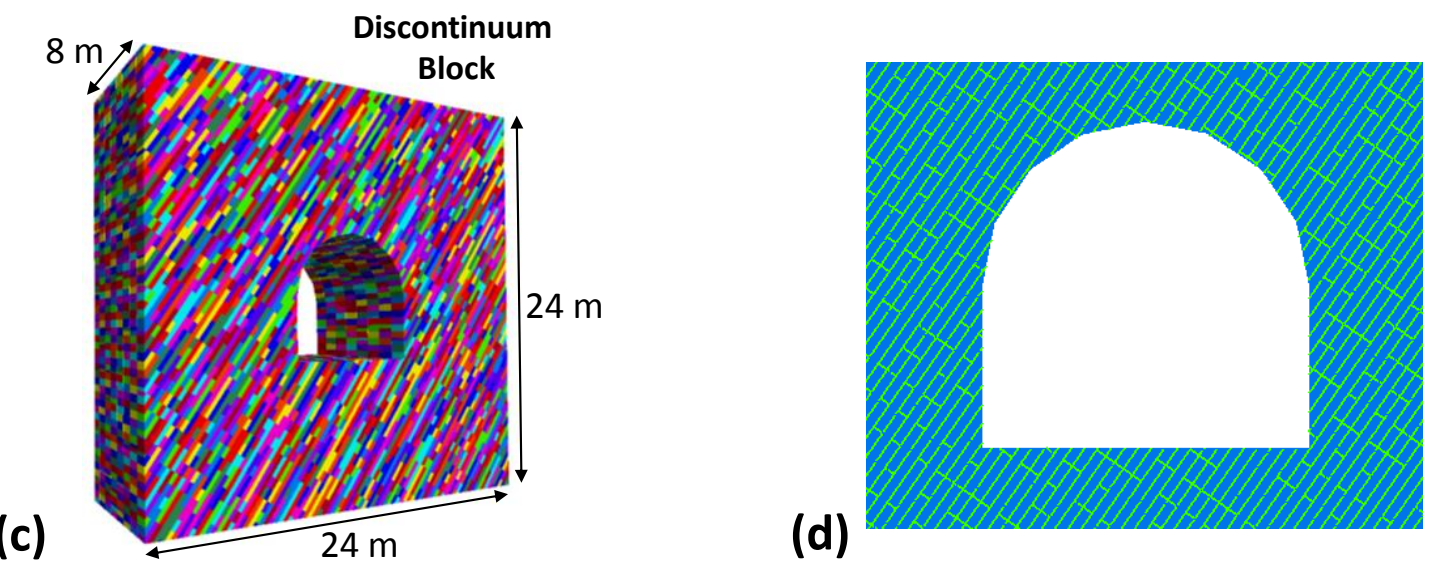

Figure 4 3DEC model: (a) geometry of the ubiquitous jointed block; (b) location of the discontinuum block relative to the main drift; (c) explicit representation of the three joint sets within the discontinuum block at the North site; and (d) 2D section of the drift through the discontinuum block showing the geometry and orientation of the main joint set and the cross-joints determined from underground mapping
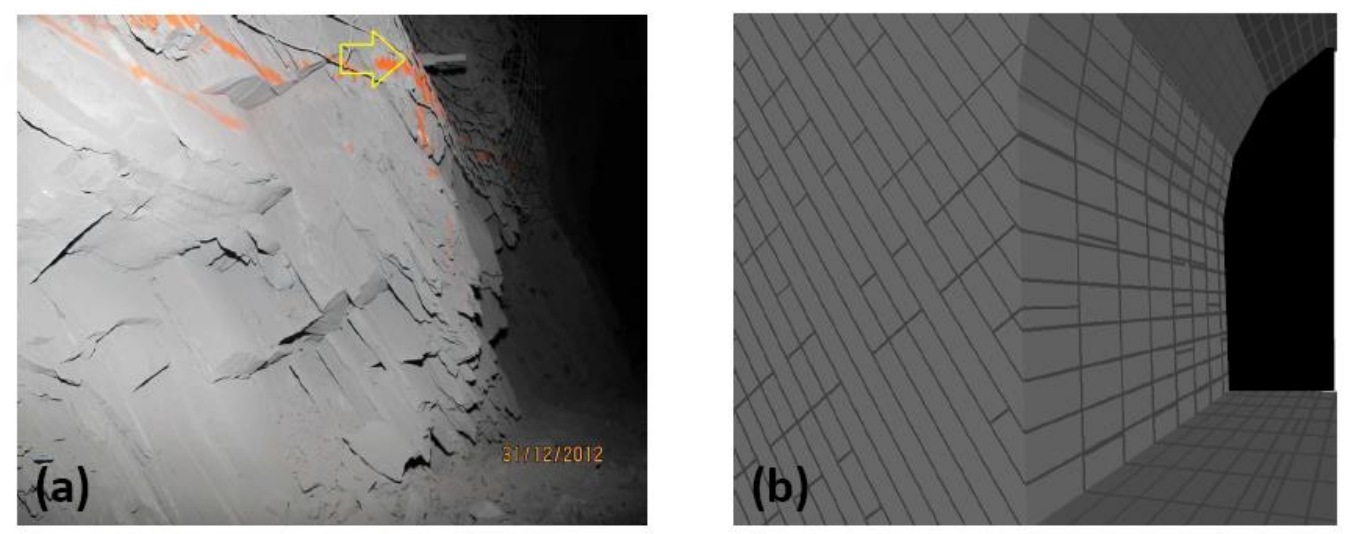

Figure 5 Comparison between the geometry of: (a) closely spaced bedding and cross-jointing at the George Fisher mine (Sweby et al. 2016b); and (b) the joint sets used to represent such features in the 3DEC model

The numerical simulation consisted of four main excavation stages, as illustrated in Figure 6 . Stage 1 includes the excavation of the drifts as well as the stopes that had been developed before the instruments (e.g. convergence points and SMART cables) were installed at the North site. Once Stage 1 was completed, the cable bolts representing the SMART cables are installed, all the displacements were reset to zero, and stopes 21, 23 and 29 were excavated sequentially from Stage 2 to Stage 4. 

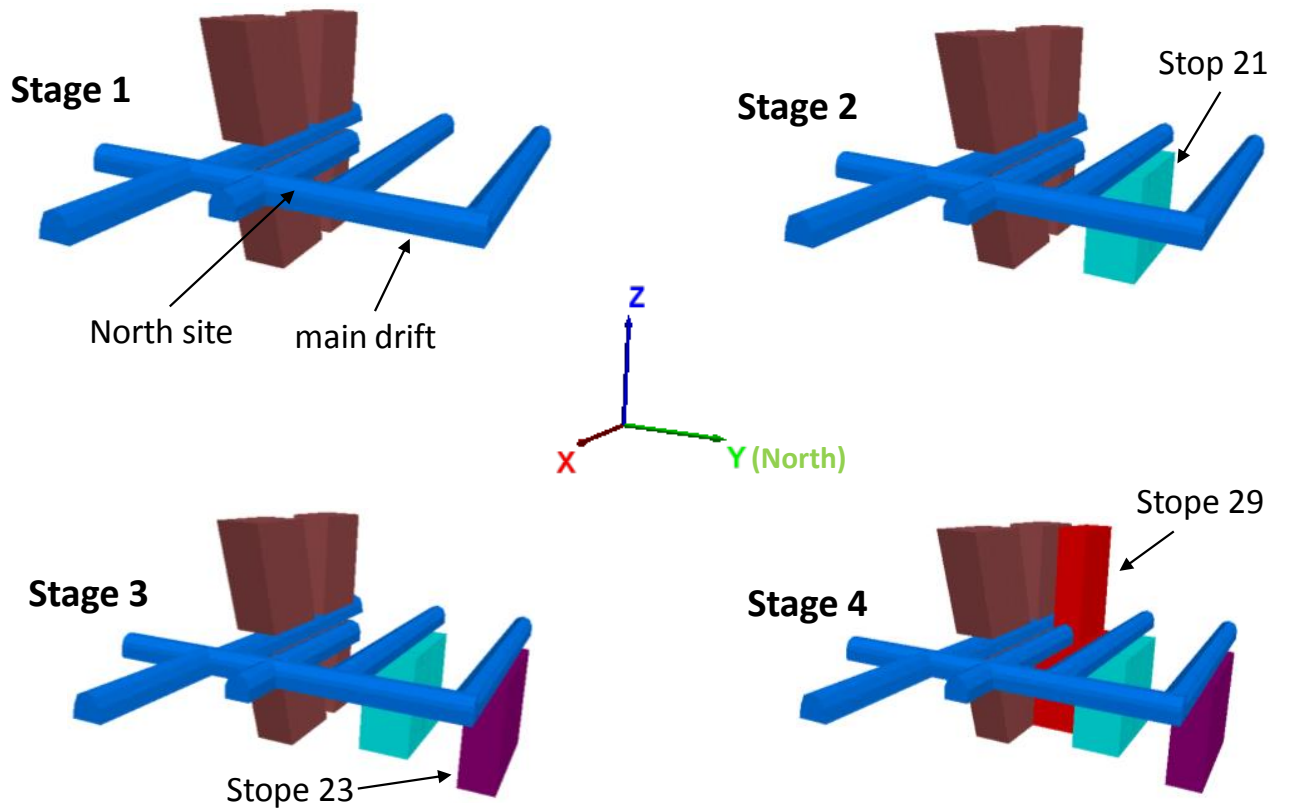

Figure 6 Stage 1: excavation of drifts and stopes prior to installation of convergence points and SMART cable; Stage 2: excavation of Stope 21; Stage 3: excavation of Stope 23; and, Stage 4: excavation of Stope 29

\subsection{Reinforcement and support elements}

Two different support elements were used in the simulations (Figure 7):

- Liner element to simulate fibercrete.

- Cable elements to simulate the SMART cables and rockbolts.

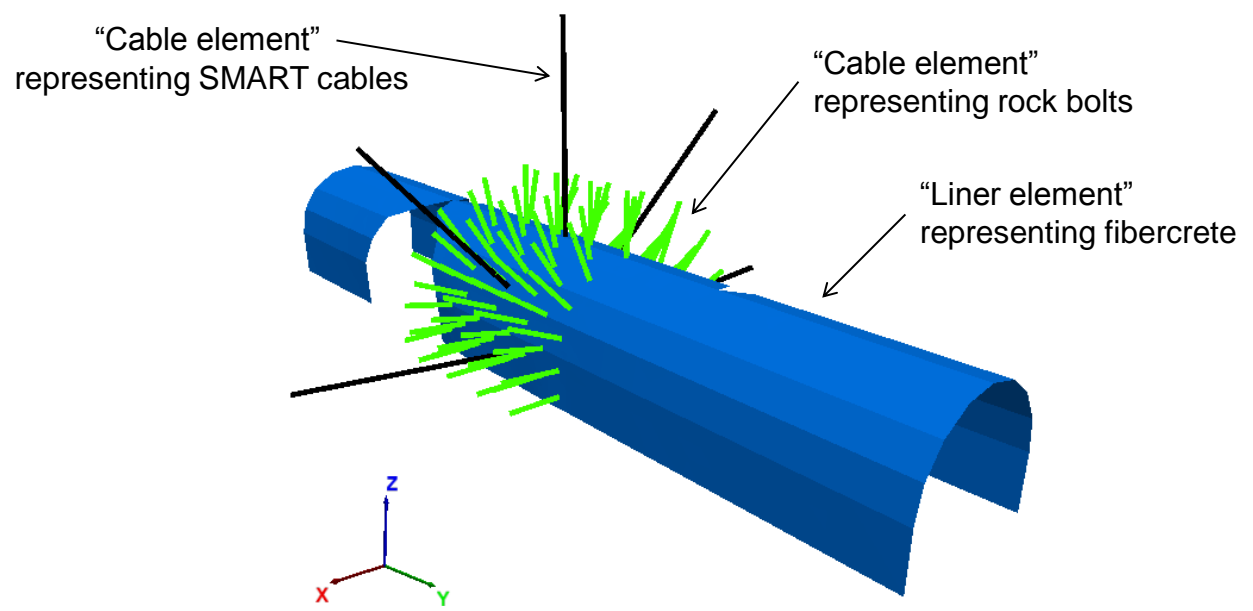

Figure 7 Liner and cable elements used to simulate fibercrete, rockbolts and the SMART cables at the North site

The liner and cable elements representing the rockbolts (green cables in Figure 7) were installed during the excavation of the drift. The purpose of simulating the fibercrete in the 3DEC model was to generate enough surface support to avoid collapse of fractured 'skin'. As previously indicated, the cable elements representing the SMART cables (black cables in Figure 7) were installed once the excavation of the drifts was completed, just before Stope 21 was excavated at Stage 2, as shown in Figure 6. Further information about the properties of the reinforcement and support elements is provided in the next section. 


\subsection{Model calibration and input parameters}

The selection of appropriate input parameters to run numerical models is always a challenge and has to account for both a degree of variability and uncertainty. The in situ stress magnitudes and orientations obtained from field measurements using the hollow inclusion (HI) cells were directly used in the 3DEC model (Table 1).

Table 1 In situ stress values used in 3DEC model

\begin{tabular}{llll}
\hline Principal stress component & Value & Dip & Azimuth \\
\hline Major & $45 \mathrm{MPa}$ & $24^{\circ}$ & $62^{\circ}$ \\
\hline Intermediate & $38 \mathrm{MPa}$ & $5^{\circ}$ & $154^{\circ}$ \\
\hline Minor & $27 \mathrm{MPa}$ & $65^{\circ}$ & $256^{\circ}$ \\
\hline
\end{tabular}

Table 2 lists the intact rock properties obtained from laboratory unconfined compression tests on three different rock types (Villaescusa 1997). Initially, the average intact rock properties, listed in Table 2, were used in the 3DEC model. It was found that the drift deformation predicted by the 3DEC model was not consistent with that measured in the field. Therefore, the model input parameters including the stiffness, strength and frictional properties of the intact rock and the joints had to be revised using a calibration process. As a reference point, the calibration was conducted with respect to the drift convergence measured following the excavation of Stope 29.

Table 2 Intact rock properties obtained from laboratory tests (Villaescusa 1997)

\begin{tabular}{llll}
\hline Rock type & UCS & Young's modulus & Poisson's ratio \\
\hline Pyrite shale & $117 \mathrm{MPa}$ & $96 \mathrm{GPa}$ & 0.34 \\
Shale siltstone & $122 \mathrm{MPa}$ & $85 \mathrm{GPa}$ & 0.26 \\
Massive siltstone & $133 \mathrm{MPa}$ & $104 \mathrm{GPa}$ & 0.33 \\
Average & $124 \mathrm{MPa}$ & $95 \mathrm{GPa}$ & 0.31 \\
\hline
\end{tabular}

The geological strength index from field investigation (Sweby, personal communication, 2016) was estimated about 50. Assuming the average intact rock elastic modulus is $95 \mathrm{GPa}$ (Table 2), the simplified Hoek and Diederichs equation (Hoek \& Diederichs 2006) yields a rock mass elastic modulus of $29 \mathrm{GPa}$. This value, along with an average intact rock elastic modulus of $95 \mathrm{GPa}$ were used for the continuous and discontinuous blocks in the 3DEC model and were kept as fixed values during the course of model calibration. To match the drift closure with the convergence monitoring data using the tape extensometer and the SMART cable, a series of sensitivity analyses was conducted to assess the influence of joint normal and shear stiffness on the deformation of the drift (assuming the joint normal to shear stiffness ratio is 10). It was found that values of 180 and $18 \mathrm{GPa} / \mathrm{m}$ for the joint normal and shear stiffness would result in a drift wall deformation similar to that obtained from field measurements (Sweby et al. 2016b). Unfortunately, no data regarding the joint strength and frictional properties was available and, therefore, reasonable assumptions had to be made during the calibration process. Table 3 lists the calibrated model input parameters. 
Table 3 Discontinuum block (intact rock and joints) and continuum ubiquitous block properties

\begin{tabular}{|llll}
\hline Discontinuum block properties & & \multicolumn{2}{l}{ Continuum ubiquitous block properties } \\
\hline Intact rock Young's modulus & $95 \mathrm{GPa}$ & Rock mass Young's modulus & $29 \mathrm{GPa}$ \\
\hline Poisson's ratio & 0.31 & Poisson's ratio & 0.31 \\
\hline Density & $2,700 \mathrm{~kg} / \mathrm{m}^{3}$ & Density & $2,700 \mathrm{~kg} / \mathrm{m}^{3}$ \\
\hline Intact rock cohesion & $7.5 \mathrm{MPa}$ & Intact rock cohesion & $7.5 \mathrm{MPa}$ \\
\hline Intact rock tensile strength & $0.2 \mathrm{MPa}$ & Intact rock tensile strength & $0.2 \mathrm{MPa}$ \\
\hline Intact rock friction angle & $20^{\circ}$ & Intact rock friction angle & $20^{\circ}$ \\
\hline Intact rock dilation angle & $10^{\circ}$ & Intact rock dilation angle & $10^{\circ}$ \\
\hline Joint cohesion & $1.0 \mathrm{MPa}$ & UJ cohesion & $1.0 \mathrm{MPa}$ \\
\hline Joint tensile strength & $0.01 \mathrm{MPa}$ & UJ tensile strength & $0.01 \mathrm{MPa}$ \\
\hline Joint friction angle & $20^{\circ}$ & UJ friction angle & $20^{\circ}$ \\
\hline Joint dilation angle & $10^{\circ}$ & UJ dilation angle & $10^{\circ}$ \\
\hline Joint normal stiffness & $180 \mathrm{GPa} / \mathrm{m}$ & & \\
\hline Joint shear stiffness & $18 \mathrm{GPa} / \mathrm{m}$ & & \\
\hline
\end{tabular}

UJ stands for ubiquitous joint

The properties of the liner elements used to simulate fibercrete and the cable elements used to simulate the SMART cables and rockbolts are provided in Tables 4 and 5, respectively. These properties were derived from manufacturers' specifications for reinforcement, published values for grout and fibrecrete and from onsite quality control. The liner thickness was determined by photogrammetry scans conducted before and after the application of fibrecrete (see Figure 2). In the numerical simulations, it was assumed that there was no relative movement, or slip, between the shotcrete liner and the rock during drift and stope excavations. Therefore, an infinite strength value was assigned to the rock-liner interface. The frictional strength and stiffness properties of the liner-rock contact were obtained from the results of laboratory tests reported by Saiang et al. (2005).

Table 4 Properties of 3DEC liner element

\begin{tabular}{ll}
\hline Shotcrete liner properties & Value \\
\hline Thickness & $0.15 \mathrm{~m}$ \\
\hline Poisson's ratio & 0.25 \\
\hline Elastic modulus & $20 \mathrm{GPa}$ \\
\hline Density & $2 \mathrm{t} / \mathrm{m}^{3}$ \\
\hline Friction angle & $40^{\circ}$ \\
\hline Tensile strength & Infinite \\
\hline Cohesion & Infinite \\
\hline Rock-liner contact normal stiffness & $250 \mathrm{GPa} / \mathrm{m}$ \\
\hline Rock-liner contact shear stiffness & $1 \mathrm{GPa} / \mathrm{m}$ \\
\hline
\end{tabular}


Table 5 Properties of 3DEC cable elements representing the SMART cables and rockbolts (Sweby et al. 2016b)

\begin{tabular}{llll}
\hline $\begin{array}{l}\text { Cable element properties } \\
\text { (SMART cable) }\end{array}$ & Value & $\begin{array}{l}\text { Cable element } \\
\text { properties (rockbolts) }\end{array}$ & Value \\
\hline Cable modulus & $195 \mathrm{GPa}$ & Cable modulus & $205 \mathrm{GPa}$ \\
Cross-sectional area & $1.43 \times 10^{-4} \mathrm{~m}^{2}$ & Cross-sectional area & $3 \times 10^{-4} \mathrm{~m}^{2}$ \\
Tensile strength & $0.2 \mathrm{MN}$ & Tensile strength & $0.25 \mathrm{MN}$ \\
\hline Grout stiffness & $670 \mathrm{MPa} / \mathrm{m}$ & Grout stiffness & $670 \mathrm{MPa} / \mathrm{m}$ \\
\hline Grout cohesion & $1.5 \mathrm{MPa}$ & Grout cohesion & $2 \mathrm{MPa}$ \\
\hline
\end{tabular}

Figure 8 compares the actual and modelled drift convergence. It can be seen that the 3DEC model underestimates the drift convergence measured after the excavations of Stopes 21 and 23 at six sections at the North site (CP1 to CP6), while it realistically predicts the convergence measured following the excavation of Stope 29. Sweby et al. (2016a) reported a similar model response from the mine-scale FLAC3D model. In the following sections, the results of the calibrated 3DEC model, including the induced stresses and displacements, intact rock and joint failure modes, as well as the axial load distributions along the cable elements, are discussed.

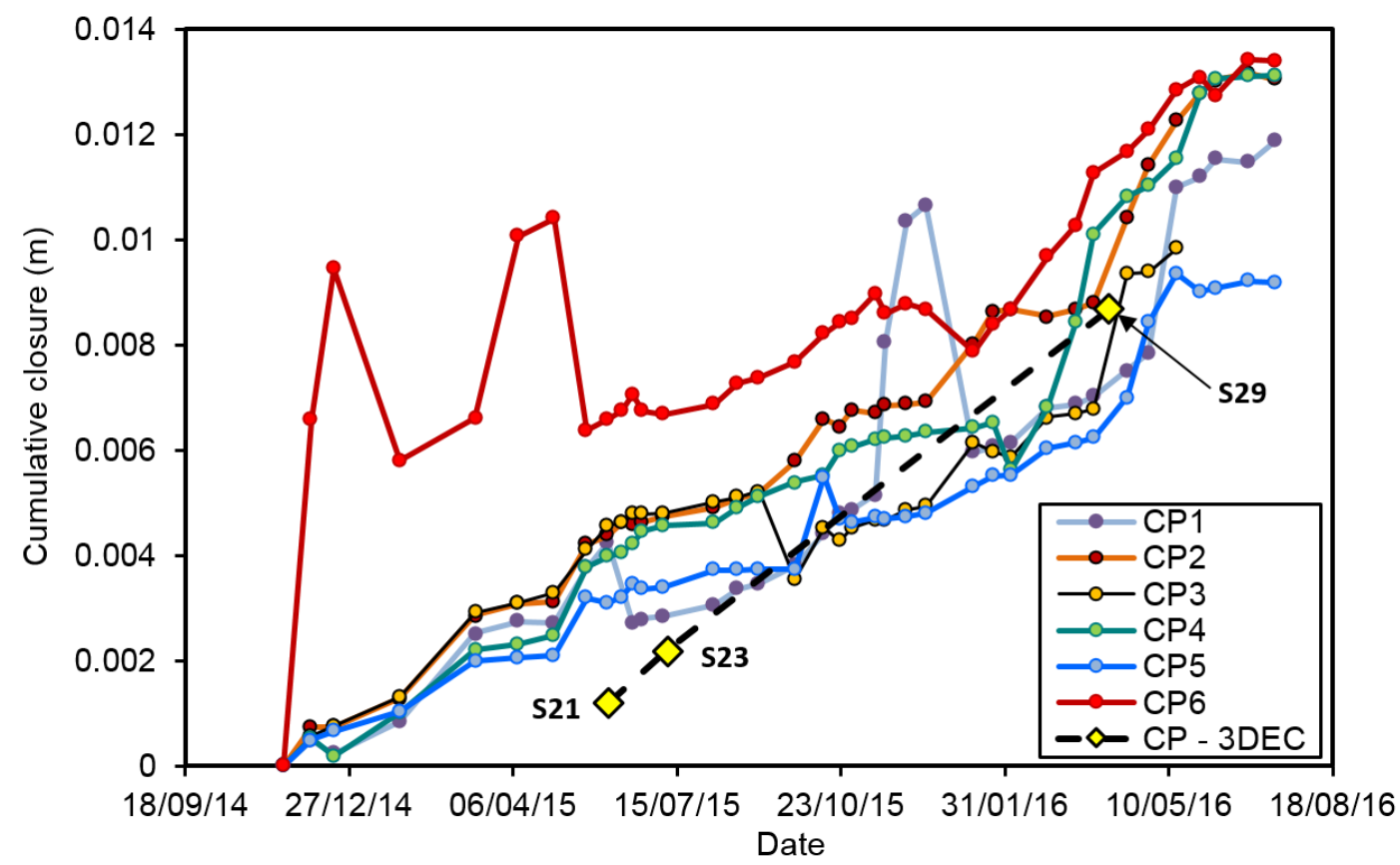

Figure 8 Comparison between modelled and measured drift convergence at the North site. S21, S23 and S29 stand for Stopes 21, 23 and 29

\section{$4 \quad$ Modelling results}

\subsection{Induced stresses and displacements}

Figure 9 shows contours of maximum $\left(\sigma_{1}\right)$ and minimum $\left(\sigma_{3}\right)$ principal stresses after the excavation of drift (Stage 1 in Figure 6). It can be seen from the results of elastic analysis (both block and joint behaviours are perfectly plastic) (Figures 9(a) and 9(c)) that the top right and lower left sides of the drift experience higher stress concentrations, whereas the sidewalls and the floor are in tension. Figures 9 (b) and 9 (d) illustrate the stress redistribution after the rock mass yields near the drift. In this case, both the maximum and minimum principal stresses are nearly zero close to the drift boundaries. 

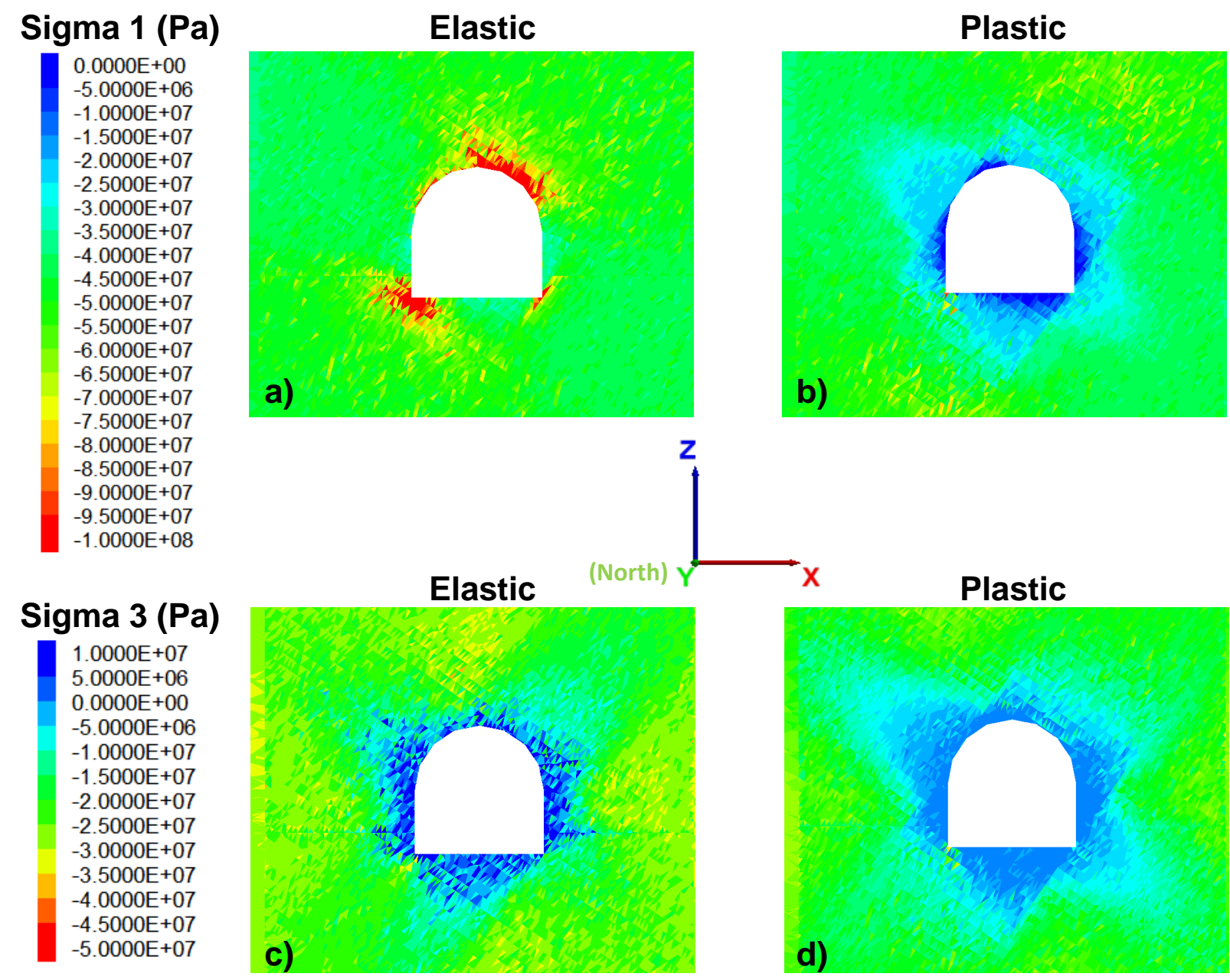

Figure 9 Contours of maximum and minimum principal stresses after the excavation of drift (Stage 1 in Figure 6): (a) and (b) $\sigma_{1}$ contours from elastic and plastic models; (c) and (d) $\sigma_{3}$ contours from elastic and plastic models. Note that positive value indicates compression and negative value indicates tension

The core replacement approach (Vlachopoulos \& Diederichs 2014) was used to excavate the drifts at Stage 1 in Figure 6. This was done in seven steps. In this approach, the elastic modulus of the core (i.e. drift) at step 1 is the same as that of the rock. In subsequent stages, the elastic modulus of the core is gradually reduced until the last stage where the core is excavated. Figure 10 shows a plot of the ratio of the core elastic modulus to intact rock elastic modulus versus horizontal displacements of the three monitoring points. As can be seen from Figure 10, initially, the deformation response of the three monitoring points is linear, and then becomes non-linear in the subsequent stages, which indicates rock mass yielding near the drift. 


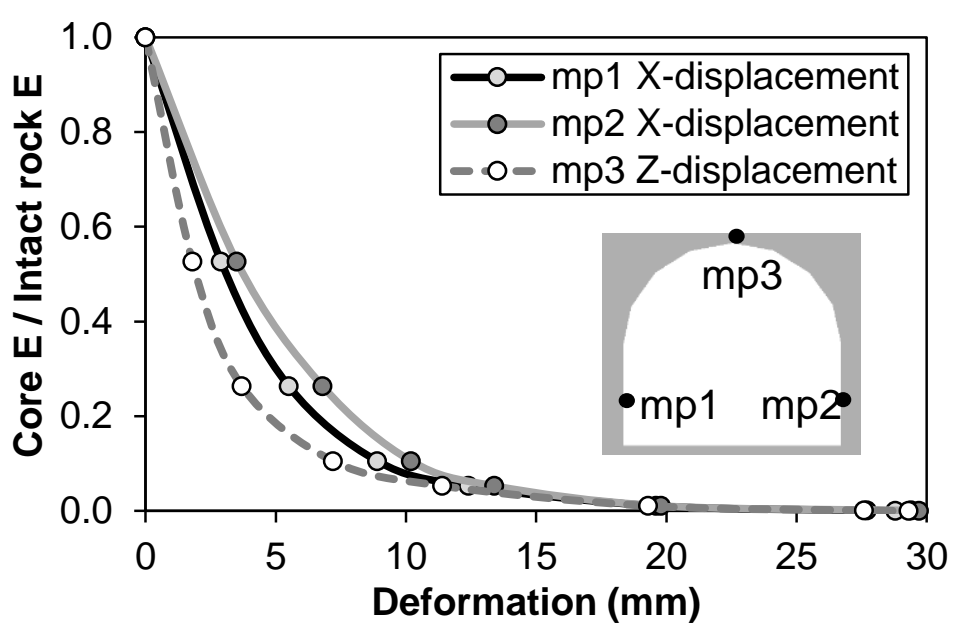

Figure 10 Deformation of three monitoring points $(\mathrm{mp})$ at the drift boundary due to the reduction in the core modulus of the drift (i.e. core replacement approach)

Figure 11 compares the displacement contours and vectors (from the elasto-plastic model) after the excavations of the drift (Stage 1 in Figure 6) and the nearby stopes (Stage 4 in Figure 6). Figure 11(a) demonstrates the convergence of the drift walls after its excavation. The displacement contours shown in Figure 11(b) are relative to Stage 1 and, therefore, demonstrate the displacement that occurred due to the excavations of nearby stopes. It can be extrapolated from the direction of the displacement vectors in Figure 11(b) that the rock mass moves to the west where the stopes are located. Only a small section of the rock mass on the left side of the drift tends to displace towards the drift.

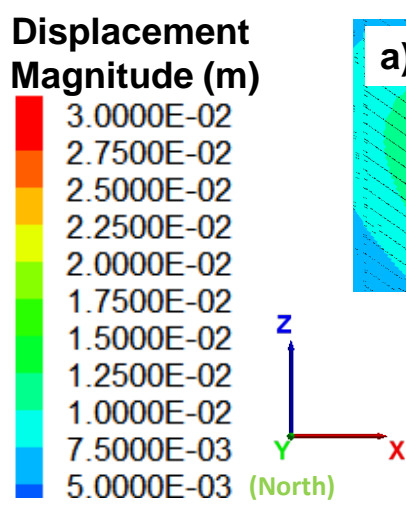

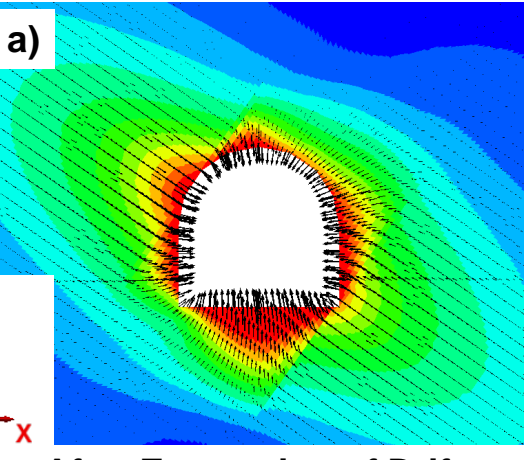

After Excavation of Drift

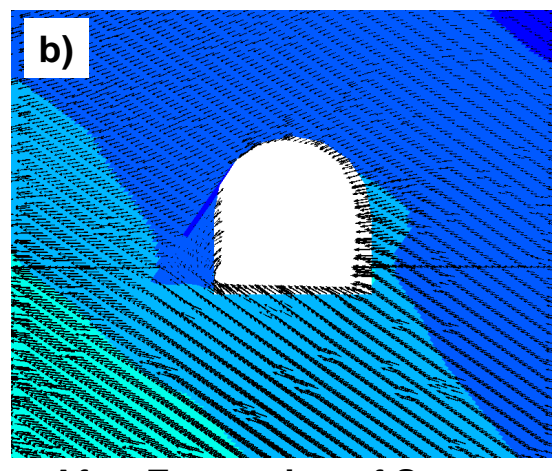

After Excavation of Stopes

Figure 11 Displacement contours and vectors near the drift at two stages: (a) after the excavation of the main drift (Stage 1 in Figure 6); and (b) after the excavation of Stope 29 (Stage 4 in Figure 6). Note that the displacements shown in (b) are relative to Stage 1 and, therefore, demonstrate the displacement that occurred following to the excavations of the nearby stopes

\subsection{Failure modes}

The failure modes of the rock mass (intact rock and joints) near the drift at the North site predicted by the 3DEC model are shown in Figures 12 and 13. Figures 12(a) and (12b) show the locations of intact rock yielding due to the excavation of the drift and Stope 29 at Stages 1 and 4, respectively. As can be seen in Figure 12(a), the intact rock yielding occurs in a pattern that is more dominant on the top right and bottom left of the drift. These locations correspond to the high stress concentration zones presented in Figure 9(a). Figure 12(b) demonstrates how the excavations of the nearby stopes resulted in the extension of the yielded zone to the west, where the stopes are located. Moreover, the depth and width of the yielded zones located on the top right and bottom left of the drift have been increased after the stope excavation was completed. This is illustrated by comparing Figures 12 . 


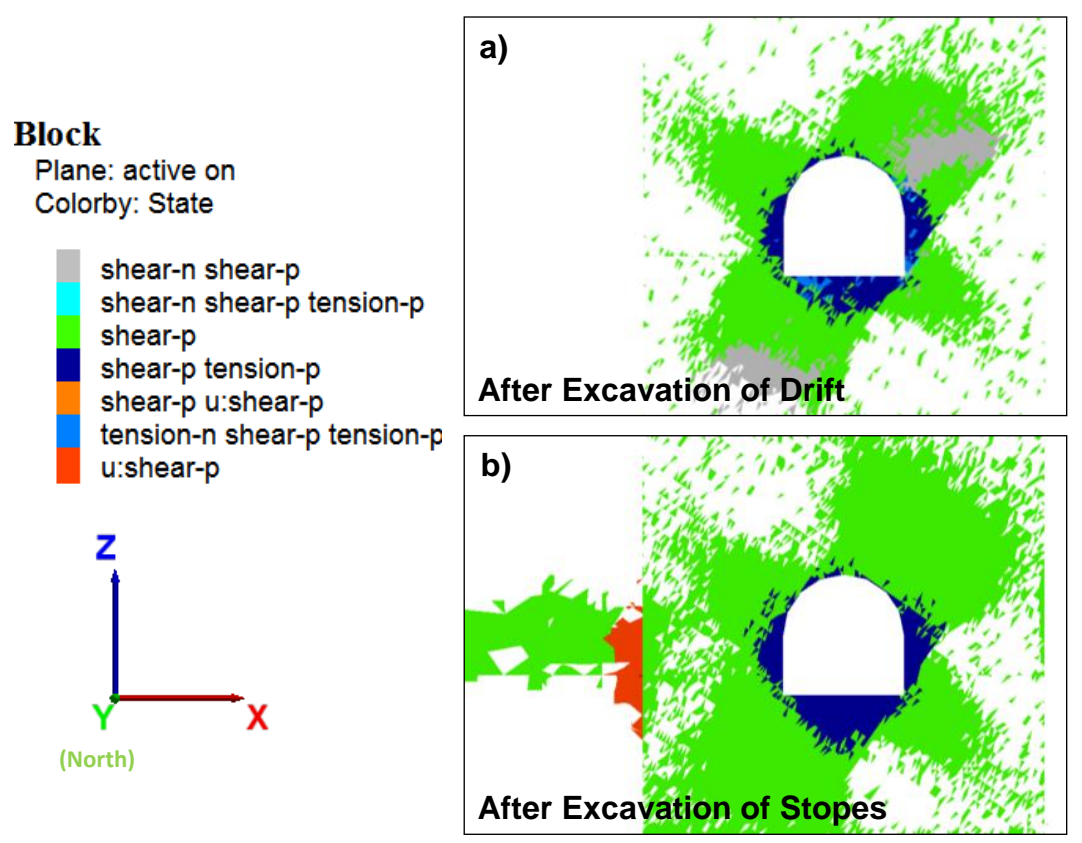

Figure 12 Modelled failure modes of intact rock and rock mass at the North site at two stages: (a) after the excavation of the main drift (Stage 1 in Figure 6); and (b) after the excavation of Stope 29 (Stage 4 in Figure 6)

Figures 13(a) and 13(b) show the joint slip that occurred after the excavation of the main drift (Stage 1 in Figure 6) and the nearby stopes (Stage 4 in Figure 6), respectively. The locations of the joint slip in Figure 13(a) correspond to the stress relaxation zones discussed in the previous section and shown in Figure 9(c). Similar to the intact rock yielding pattern (Figure 12), it can be concluded from Figures 13 that the extent of the joint slip near the drift increases from Stage 1 to Stage 4. This is evident on the west side of the drift, where the stopes are located.
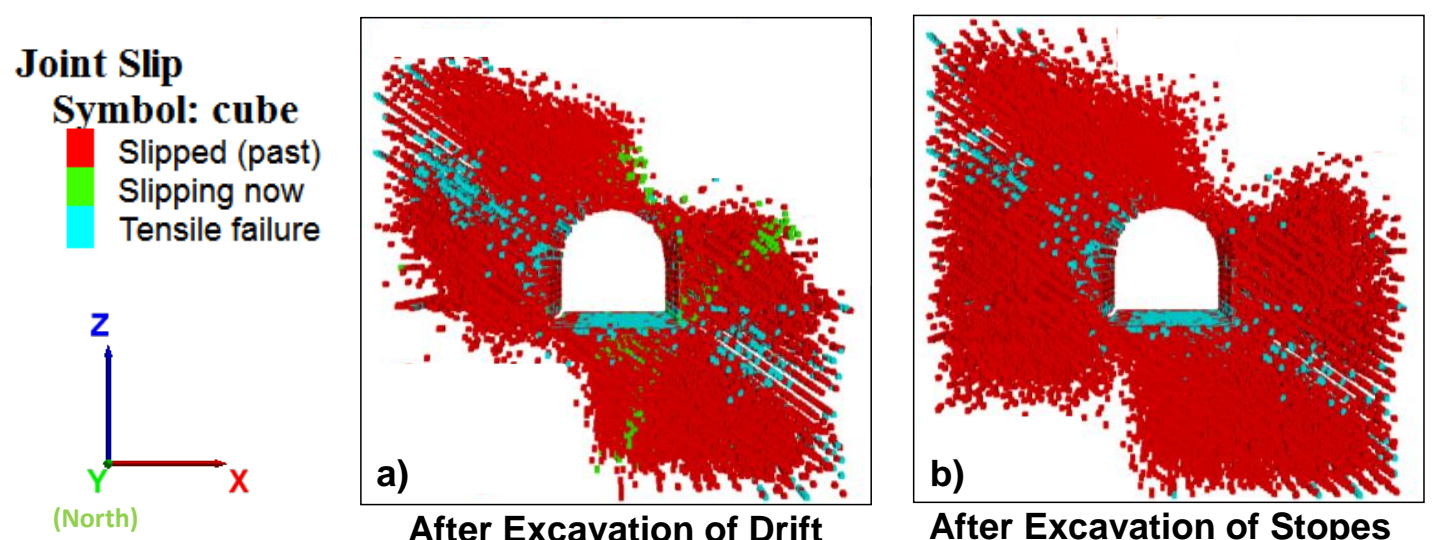

Figure 13 Modelled joint slip at the North site at two stages: (a) after the excavation of the main drift (Stage 1 in Figure 6); and (b) after the excavation of Stope 29 (Stage 4 in Figure 6)

\subsection{Cable loads}

The distributions of axial loads along the cables after the excavation of all three stopes (Stage 4 in Figure 6) are presented in Figure 14. Note that a negative load value means that the cable is under tension. It is evident from this figure that only the sidewall cables are under tension. This is consistent with field data as only the sidewall SMART cables showed appreciable load (Sweby et al. 2016b). It can be derived from Figure 14 that the cable on the west side is under higher load than that on the east side. 

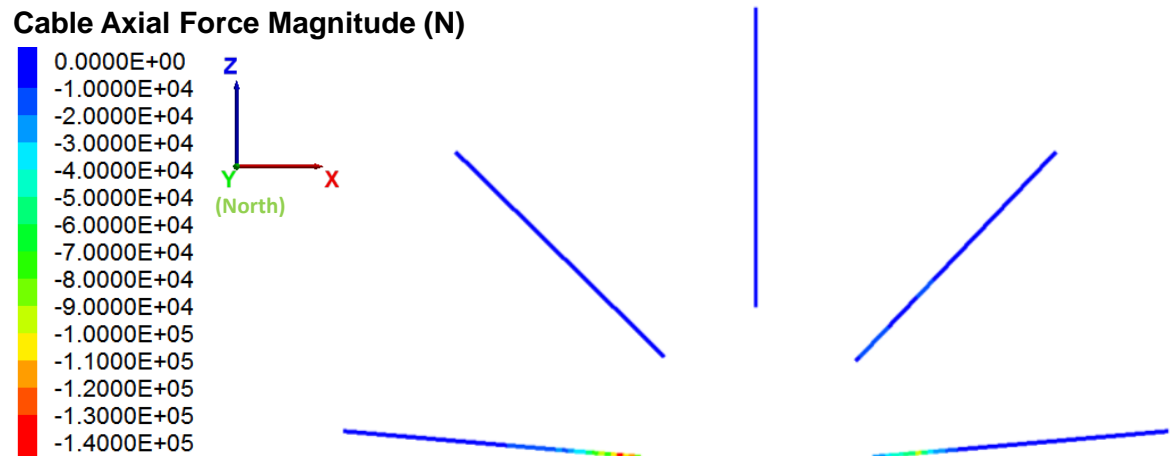

Figure 14 Contours of axial forces along the cable elements representing the SMART cables after excavation of stope 29

\section{Comparison with SMART cable data}

Figure 15 compares the axial load distribution along the cable elements after the excavation of Stope 29 (Stage 4 in Figure 6) with those measured from the sidewall SMART cables at the North site. It can be seen from Figure 15 that the measured load from the SMART cable is relatively low at the instrument collar (about zero in the case of the east cable and about two tonnes in the case of the west cable). The measured load in both cables increases to its maximum value at less than $2 \mathrm{~m}$ away from the collar, and then gradually decreases to zero at $8 \mathrm{~m}$ from the collar.

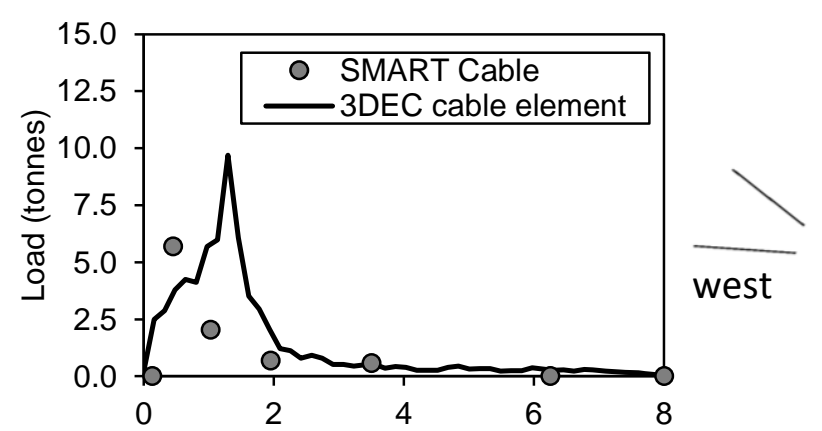

a) Distance from excavation boundary $(\mathrm{m})$

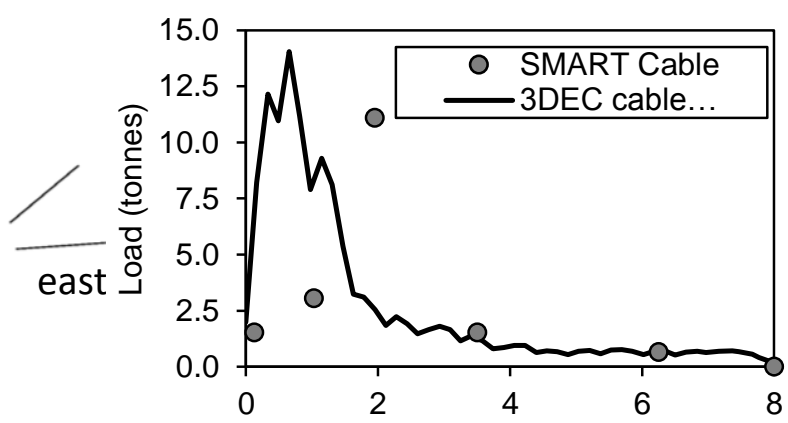

b) Distance from excavation boundary ( $\mathrm{m})$

Figure 15 Comparison between the measured and modelled axial loads along the cables on the (a) east and (b) west sides of the drift after the excavation of Stope 29 (Stage 4 in Figure 6)

Interestingly, the modelled cables show loads comparable to the measured values at the collar of both cables. The modelled peak loads occur at 1.3 and $0.7 \mathrm{~m}$ away from the drift walls in the east and west cables, respectively. In both cases, the modelled axial load gradually decreases, after its peak, with increasing the distance from the drift wall until it reaches zero at the end of the cable.

A comparison between the measured and modelled loads in Figure 15 suggests that the maximum load measured along the SMART cable is overestimated by the cable element by about four tonnes in the case of the east cable and by about three tonnes in the case of the west cable. The decrease in the load with increasing distance from the collar is, however, captured reasonably well by the 3DEC cable elements. Considering the variations between the measured and modelled load along the cable, it is concluded that the axial loads predicted by the cable element in 3DEC are acceptable for most practical purposes.

\section{Discussion and conclusions}

A 3DEC model was built to explicitly simulate the discontinuous nature of the jointed rock mass and support system consisting of fibercrete liner, rockbolts and SMART cables at an instrumented trial site in the George Fisher mine, Queensland, Australia. The numerical simulation was conducted to investigate the deformation 
of the rock mass near the drift, as well as the loads developed along the SMART cables due to the excavation of nearby stopes. In general, the axial loads developed along the cable elements in the 3DEC model were found to be in accordance with field observations in terms of their trends with increasing distance from the borehole collar and their magnitudes. It was found that the modelled cables overestimated the maximum load developed in the SMART cables, which occurs within the first $2 \mathrm{~m}$ from the drift wall. However, they captured the reduction in the loads with increasing distance from the borehole collar.

In the numerical modelling exercise, presented in this paper, limited effort was made to capture the complexity in the geometries of the excavations such as the drifts and stopes. On the other hand, the discontinuous nature of the rock mass near the trial site (in terms of joint orientation, spacing and persistence) was simulated as close as possible to the field condition. In the future, the influence of such complexities in the shape of the excavations can be investigated. Furthermore, the simulations can be made more realistic by considering the drift advance and support installation timing, stope backfill, and introduction of rock property variability. Further investigation is underway to validate the results of numerical modelling with further monitoring instruments installed at the North site.

\section{Acknowledgement}

The Australian Centre for Geomechanics (ACG) provided the data required to conduct this research. Gordon Sweby is gratefully acknowledged for many discussions on the instrumentation and in interpreting and comparing the results between FLAC3D and 3DEC models. The authors further thank Jim Hazzard from the Itasca Consulting Group for providing technical support on 3DEC modelling. This research was supported by Natural Sciences and Engineering Research Council of Canada (NSERC).

\section{References}

DeGraff, PH, Hyett, AJ, Lausch, P, Bawden, WF \& Yao, M 1999, 'Investigations into the distribution of load along cable bolts - a field trial using 'SMART TECHNOLOGY', an aid to successful ground support design', Proceedings of the 9th ISRM Congress, International Society for Rock Mechanics, Lisboa, pp. 1273-1277.

Hoek, E \& Diederichs, MS 2006, 'Empirical estimation of rock mass modulus', International Journal of Rock Mechanics and Mining Sciences, vol. 43, pp. 203-215.

Itasca Consulting Group, Inc. 2013, 3DEC - Distinct Element Modeling of Jointed and Blocky Material in 3D, software, version 5.0, Itasca Consulting Group, Inc., Minneapolis.

Karampinos, E, Hadjigeorgiou, J, Hazzard J \& Turcotte, P 2015, 'Discrete element modelling of the buckling phenomenon in deep hard rock mines', International Journal of Rock Mechanics \& Mining Sciences, vol. 80, pp. 346-356.

Lilley, CR, Roberts, T, Putzar G \& Beck, DA 2013, 'Dynamic simulations of excavations with yielding bolts', in Y Potvin \& B Brady (eds), Proceedings of the Seventh International Conference on Ground Support in Mining and Underground Construction, 13-15 May 2013, Perth, Australian Centre for Geomechanics, Perth, pp. 525-538.

Lorig, LJ \& Varena, P 2013, 'Guidelines for numerical modelling of rock support for mines', in Y Potvin \& B Brady (eds), Proceedings of the Seventh International Conference on Ground Support in Mining and Underground Construction, 13-15 May 2013, Perth, Australian Centre for Geomechanics, Perth, pp. 81-105.

Saiang, D, Malmgren, L \& Nordlund E 2005, 'Laboratory tests on shotcrete-rock joint in direct shear, tension and compression', Rock Mechanics and Rock Engineering, vol. 38, pp. 275-297.

Starfield, AM \& Cundall, PA 1988, 'Towards a methodology for rock mechanics modelling', International Journal of Rock Mechanics and Mining Sciences \& Geomechanics Abstract, vol. 25, no. 3, pp. 99-106.

Sweby, G, Dight, P \& Potvin, Y 2016a, 'A numerical modelling case study - correlation of ground support instrumentation data with a three dimensional inelastic model', in E Nordlund, TH Jones \& A Eitzenberger (eds), Proceedings of the Eighth International Symposium on Ground Support in Mining and Underground Construction, 12-14 September 2016, Luleå University of Technology, Luleå.

Sweby, G, Dight, P, Potvin, Y \& Gamble, N 2016b, 'An instrumentation project to investigate the response of a ground support system to stoping induced deformation', in E Nordlund, TH Jones \& A Eitzenberger (eds), Proceedings of the Eighth International Symposium on Ground Support in Mining and Underground Construction, 12-14 September 2016, Luleå University of Technology, Luleå.

Vakili, A, Sandy, MP, Mathews, M \& Rodda, B 2013, 'Ground support design under highly stressed conditions', in Y Potvin \& B Brady (eds), Proceedings of the Seventh International Conference on Ground Support in Mining and Underground Construction, 13-15 May 2013, Perth, Australian Centre for Geomechanics, Perth, pp. 551-564.

Villaescusa, E 1997, Rock mechanics studies at the George Fisher Project, technical report, Mount Isa Mines Limited.

Vlachopoulos, N \& Diederichs, MS 2014, 'Appropriate uses and practical limitations of 2D numerical analysis of tunnels and tunnel support response', Geotechnical and Geological Engineering, vol. 32, pp. 469-488. 